\title{
Interacção do ião uranilo com ácidos hidroxicarboxílicos de relevância biológica
}

\section{Introdução}

Nesta comunicação, registam-se os principais métodos e resultados da investigação realizada sobre complexos de urānio(VI) com a participação do autor [1-8]. Além do interesse científico, estes complexos têm relevância prática, quer no domínio ambiental (por exemplo, na remoção do elemento urânio de solos e, em particular, como modelos para a acção de ácidos húmicos), quer no âmbito biológico (por exemplo, no combate à intoxicação por urânio). O seu interesse químico decorre, desde logo, da geometria linear do oxoião uranilo, $\mathrm{UO}_{2}{ }^{2+}$, forma habitual do centro metálico nos complexos, com ligandos no plano equatorial, assim como da competição entre a complexação e reacçōes de hidrólise com formação de várias espécies (uranatos) em função do pH.

Os ligandos utilizados até agora foram os ácidos $\alpha$-hidroxicarboxílicos mais conhecidos: ácido láctico, ácido málico, ácido tartárico, ácido meso-tartárico e ácido cítrico. Presentemente, estende-se o estudo a ácidos derivados de açúcares e a outras espécies de interesse biológico como pequenos péptidos.

Os objectivos principais do estudo realizado foram: a especiação em solução aquosa, função das condições de concentração e pH; a determinação da estrutura e estabilidade relativa dos complexos formados; a caracterização dos equilibrios de ácido-base relacionados com a desprotonação dos grupos $-\mathrm{OH}$; a cinética de permuta intermolecular (envolvendo o ligando livre) e intramolecular (relativa às ligaçōes U-ligando).
A técnica utilizada foi a espectroscopia RMN de ${ }^{13} \mathrm{C}$ e ${ }^{1} \mathrm{H}$, recorrendo-se também a ${ }^{17} \mathrm{O}$ nos estudos em curso. A eventual limitação aliada à utilização de uma só técnica é superada pela circunstância de os complexos em solução aquosa se encontrarem em troca lenta (na escala dos desvios químicos RMN), pelo que se obtêm espectros distintos para diferentes espécies, em oposição a técnicas centradas em grandezas médias como a potenciometria, a espectroscopia UVN, a EXAFS (de aplicação mais recente [9]), etc. Deste modo, torna-se possivel obter informação directa sobre a estequiometria e a estabilidade dos complexos através de medições de intensidade espectral.

Os locais de coordenação nos complexos são determinados a partir dos desvios químicos de ${ }^{13} \mathrm{C}$ e ${ }^{1} \mathrm{H}$ devidos à com- plexação. A conformação do ligando é estabelecida aproximadamente a partir das constantes de acoplamento vicinal $\mathrm{HH}$. Os fenómenos de troca inter- e intramolecular foram caracterizados principalmente através do comportamento da largura dos sinais e poderão sê-lo melhor no futuro com recurso a técnicas de RMN bidimensional. A esfera de coordenação do urânio poderá vir a ser adicionalmente caracterizada através dos sinais de ${ }^{17} \mathrm{O}$.

\section{Resultados}

Particular atenção mereceu o sistema $\mathrm{UO}_{2}{ }^{2+} /$ malato $\mathrm{L}$ e o sistema $\mathrm{UO}_{2}{ }^{2+} / \mathrm{mala}$ to $D, L$. Para $\mathrm{pH}$ inferior a 4 , formam-se complexos de estequiometria 2:1 (metal:ligando) e complexos 2:2, sujeitos estes a rearranjo cis-trans favorecido por protonação de grupos carboxílicos:

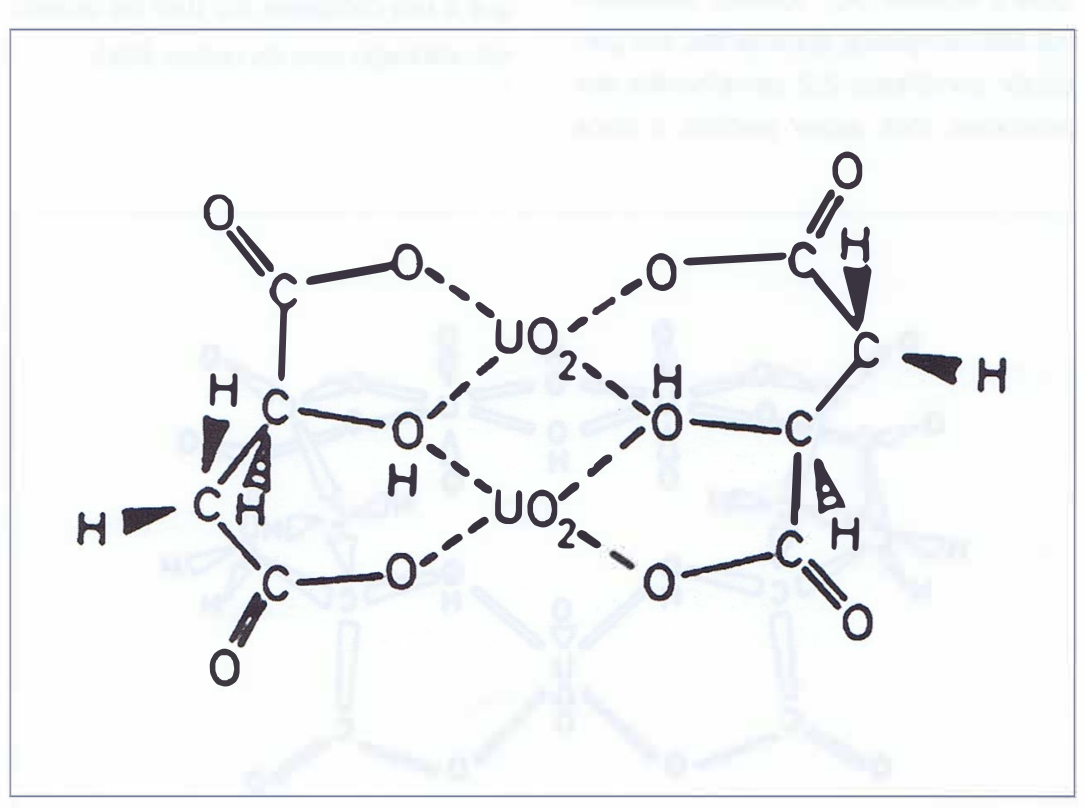

(*) Departamento de Química, Faculdade de Ciências e Tecnologia, Universidade de Coimbra (Projecto PRAXIS QUI 63/96) 
Por ionizaçāo de um grupo $-\mathrm{OH}$, a pH entre 8 e 10, surgem as bases conjugadas destes complexos 2:2, e, a pH cerca de 11-12, novas formas por ionização de todos os grupos -OH. Para a gama de $\mathrm{pH}$ entre 8 e 10, encontra-se também evidência para um complexo 4:2 em seus isómeros cis-trans, cuja estrutura proposta precisa de ser confirmada.

Um total de 12 complexos é detectado no sistema $\mathrm{UO}_{2}{ }^{2+} /$ tartarato $\mathrm{D}$, com concentraçōes relativas função do $\mathrm{pH}$ e das concentrações de partida. Os melhor caracterizados estruturalmente são semelhantes aos complexos 2:2 no siste- ma anterior. Quando se usa a mistura racémica como ligando, surge mais um complexo, dominante entre $\mathrm{pH} 5$ e 8, em soluções $1: 1$. Possui três moléculas de ligando, duas em situação equivalente, originando um espectro $A B$ (constante de acoplamento $8 \mathrm{~Hz}$ ), e outra que mantém a simetria
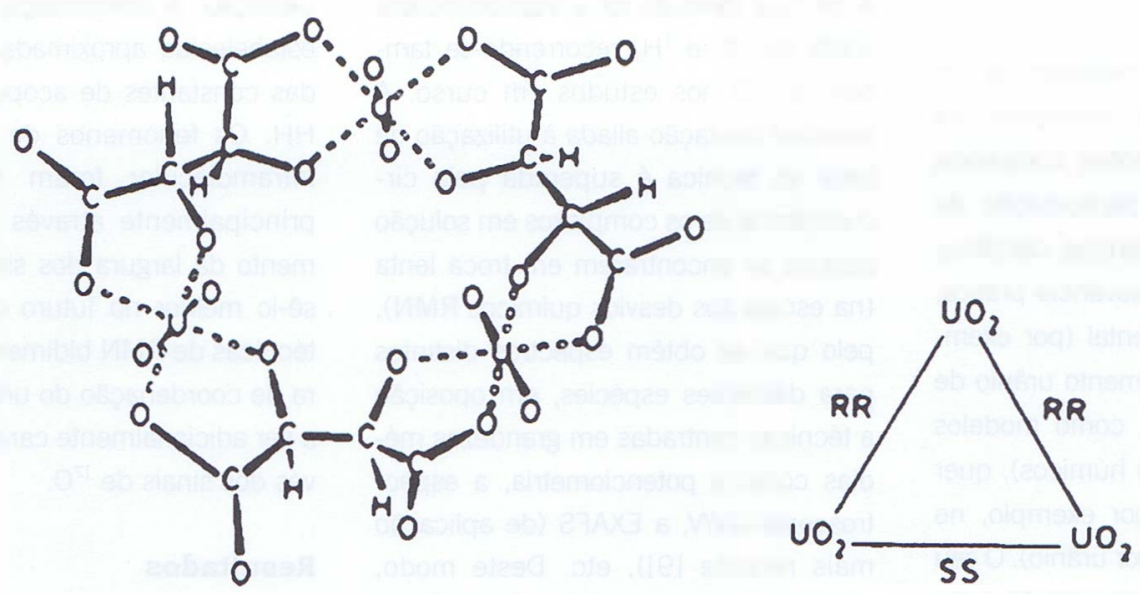

Este trímero não se forma com o tartarato meso, sistema com menos complexos, homólogos do sistema anterior e respeitando as relações de configuração esperadas para o ligando.

Com o sistema $\cup_{2}{ }^{2+} /$ citrato, detectam-se seis complexos dominantes, em particular complexos 2:2 semelhantes aos anteriores mas agora sujeitos a troca intramolecular (a pH baixo) com alternância na ligação dos grupos carboxílicos. Particular atenção mereceu a formação de um complexo muito estável (único a pH 8 numa solução 1,5:1) e que é um complexo 3:2 (um ião uranilo não alinhado com os outros dois):

\section{Referências}

1. J. Pedrosa and V.M.S.Gil, J. Inorg. Nucl. Chem. 26, 1803 (1974)

2. M.T.Nunes, V.M.S.Gil and A.V.Xavier, Can. J. Chem, 60, 1007 (1982).

3. M.T.Nunes, V.M.S.Gil and A.V.Xavier, Inorg. Chim. Acta, 95, 13 (1984).

4. M.T.Nunes and V.M.S.Gil, Inorg. Chim. Acta, 115, 107(1986)

5. M.T.Nunes and V.M.S.Gil, Inorg. Chim. Acta, 129, 283 (1987).

6. M.T.Nunes and V.M.S.Gil, Inorg. Chim. Acta, 139, 309 (1987).

7. M.T.Nunes, Tese de Doutoramento, Universidade Nova de Lisboa (1987)

8. M.T.Nunes and V.M.S.Gil, Inorg. Chim. Acta, 170, 59 (1990)

9. P.G.Allen, D.K.Shuh, J.J.Bucher, N.M.Edelstein, T.Reich, M.A.Denecke and H.Nitsche, Inorg.Chem., 35, 784 (1996). 